Research Article

\title{
Biaxial Shear Crack Propagation Modes of Rock-Like Specimens with Prefabricated Fissures and Their Strength Characteristics
}

\author{
Nai-Zhong Xu $\mathbb{D},{ }^{1}$ Chang-Qing Liu $\mathbb{D}^{2},{ }^{2}$ You-Jian Wang $\mathbb{D}^{1},{ }^{1}$ and Hong-Bin Dang $\mathbb{D}^{2}$ \\ ${ }^{1}$ Anhui University of Science \& Technology, School of Mining Engineering, Huainan 232001, China \\ ${ }^{2}$ Anhui Academy of Emergency Management Science, Hefei 230061, China
}

Correspondence should be addressed to Nai-ZhongXu; nzxu@aust.edu.cn

Received 29 April 2021; Accepted 16 July 2021; Published 3 August 2021

Academic Editor: Dan Ma

Copyright (C) 2021 Nai-Zhong Xu et al. This is an open access article distributed under the Creative Commons Attribution License, which permits unrestricted use, distribution, and reproduction in any medium, provided the original work is properly cited.

\begin{abstract}
A biaxial shear test is performed on prefabricated, single-fissure type, cubic rock-like specimens by using the TZW-500 rock direct shear apparatus to study the shear strength characteristics, crack coalescence, and propagation modes of the specimens with different geometric parameters. Results show that the crack coalescence and propagation modes of the rock-like specimens with prefabricated fissures can be divided into four types, namely, single main shear crack coalescence mode, main shear crack coalescence and secondary tensile-shear crack propagation mode, main shear crack coalescence and secondary shear crack propagation mode, and main shear crack coalescence and secondary tensile crack propagation mode. All modes are affected by the dip angle $\alpha$ and length $l$ of the prefabricated fissure. When the dip angle of the prefabricated fissure is $\alpha \in\left[0^{\circ}, 20^{\circ}\right)$ or $\left(70^{\circ}, 90^{\circ}\right]$, the cracks center on shear failure, and most shear cracks propagate along one end of the prefabricated fissure. At $\alpha \in\left(30^{\circ}, 50^{\circ}\right)$, the cracks bear the tensile-shear combined action, and the shear cracks propagate along the two ends of the prefabricated fissure. The peak shear strength of the rock-like specimens with prefabricated fissures is also closely related to the dip angle $\alpha$ and length $l$ of the fissure. With the increase in dip angle $\alpha$ of the prefabricated fissure, the peak shear strength of each rock-like specimen decreases initially then increases, and the peak shear strength curve presents a similar " $U$ " shape. At $\alpha \in\left[30^{\circ}, 60^{\circ}\right]$, the peak shear strength is within the peak-valley interval. When the length $l$ of the prefabricated fissure is increased, the peak shear strength experiences a gradual reduction. When $l>20 \mathrm{~mm}$, the peak shear strength is greatly influenced by $l$, but the influence is minimal when $l \geq 20 \mathrm{~mm}$. At the same dip angle $\alpha$ and fissure length of $l \geq 20 \mathrm{~mm}$, the correlation between peak shear strength and fissure width $b$ is low.
\end{abstract}

\section{Introduction}

Slope rock mass is a natural geologic body composed of rocks and joint surfaces with different geometrical states, and various joint fissures with different shapes and sizes generated due to weathering and corrosion usually exist in its internal space, as shown in Figure 1. In comparison with rock mass with a compact structure and good texture, rock mass under the joint action of joint surfaces and fissures has physical and mechanical parameters that deteriorate to different degrees. Studies [1-4] have shown that the mechanical properties of engineering rock mass are considerably influenced by the geometrical morphologies of the joints and fissures in the rock mass under the action of external loads. When a rock mass is under the action of external force, cracks begin to propagate outward gradually from the fissure tip inside the rock mass and run through the rock mass to generate failure. Therefore, correctly understanding the basic mechanical properties and coalescence failure mechanism of fissure-type rock mass on slopes is essential and provides an important basis for scientifically and effectively evaluating the safety and stability of slope engineering.

Model [5-13] and numerical [14-19] tests are usually used in present studies on the crack propagation mode and strength characteristics of joint fissure-containing rock mass. Luo [17] analyzed the fracture response laws of fissure- 


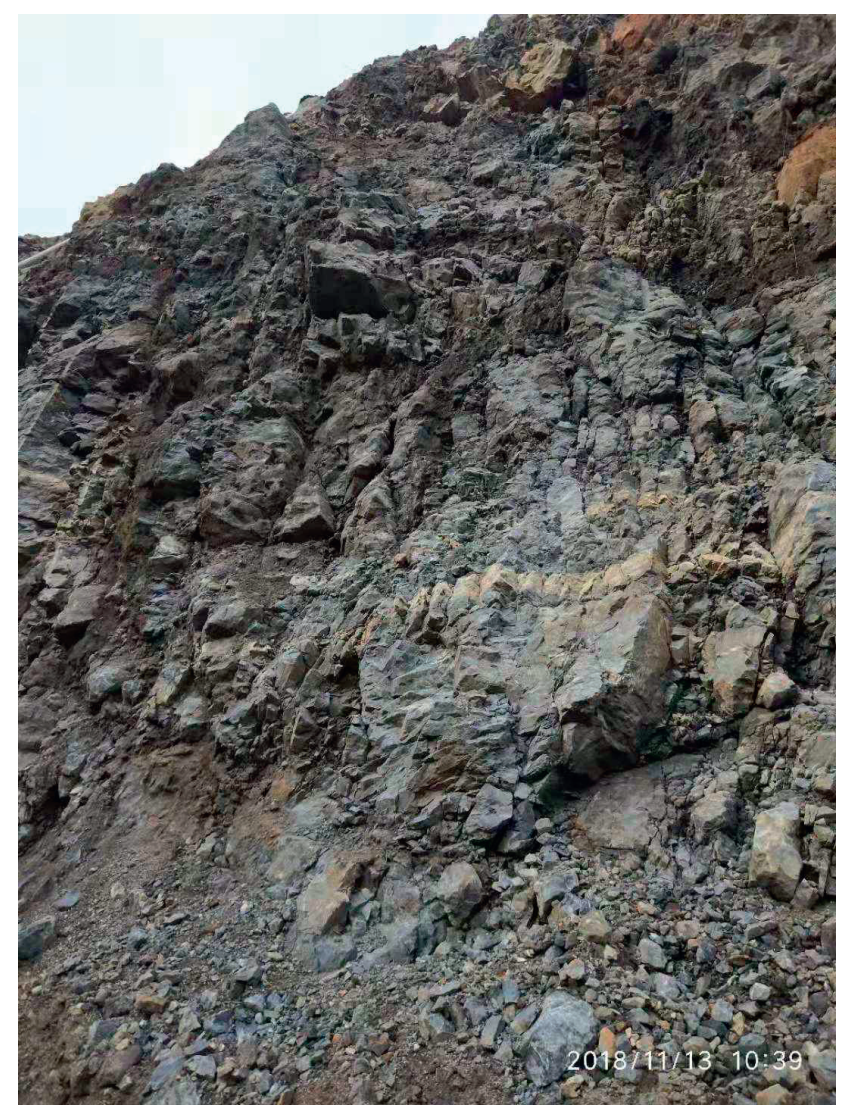

FIGURE 1: Slope of an open pit mine.

containing rock mass under the joint action of loading rate and fissure dip angle. Jooeun [18] explored the failure mechanism of three defective rock materials with different alignment defects under uniaxial compression by conducting a numerical simulation. With reference to the discrete element theory of particles, Wang [19] systematically studied the crack generation and evolution laws of stratiform rocks containing non-coplanar double fissures under a uniaxial compression condition. Zhang and Wong $[20,21]$ conducted a uniaxial compression simulation of single- and double-fissure rock specimens and analyzed the meso-force field evolution laws in the crack propagation process. Through a model material test, numerical simulation, and real rock material test, other studies [5-9, 22-26] systematically investigated the strength deformation characteristics and crack propagation modes of rock specimens containing one, two, three, or more fissures under uniaxial compression. However, the biaxial shear test method has been used in only a few studies to explore the crack propagation modes of slope rock mass.

In the current work, prefabricated rock-like specimens were adopted as study objects, and a biaxial shear test was conducted using the TZW-500 rock direct shear apparatus to study the strength characteristics of the cubic specimens with prefabricated fissures and different geometric parameters. Crack coalescence and propagation modes were also examined. The results are expected to provide a reference for rock slope engineering design and slope stability control.

\section{Preparation of Test Materials}

2.1. Test Materials and Specimen Preparation. The rock-like specimens with prefabricated fissures prepared in this test were formed through the blending and cementation of cement, sand, gypsum, and water. Through repeated trial mixing and testing, the weight ratio was determined to be cement : gypsum : sand : water $=40 \%: 8 \%: 35 \%: 17 \%$. The fissures were prefabricated through the slide-out method and filled with mica sheets.

The rock-like specimens were cubes with a side length of $10 \mathrm{~cm}$. The joint position and dimension parameters are shown in Figure 2. The length, width, and dip angle of the prefabricated fissure were denoted as $l, b$, and $\alpha$ (included angle with the horizontal plane, measured anticlockwise), respectively. The center of the prefabricated fissure overlapped with the geometric center of each cube, and the prefabricated fissure ran through the entire cube. In this test, the length $l$ of the prefabricated fissure was set to 10,20 , and $30 \mathrm{~mm}$; width $b$ was set to $0.1,0.5,0.7$, and $1 \mathrm{~mm}$; and dip angle $\alpha$ was set to $0^{\circ}-90^{\circ}$ at a progressive increase by the interval of $10^{\circ}$ (total of 10 types). Six specimens of each combination type were prefabricated. The specimens that vibrated compactly were cured at room temperature $\left(20^{\circ} \pm 1^{\circ}\right)$, and $4-5 \mathrm{~h}$ afterward, the steel sheets were pulled out to form prefabricated fissures. After one day, the rock-like specimens with prefabricated fissures were demolded, the flatness and crack coalescence condition of each specimen were examined, and the damaged specimens or those that do not meet the requirements were excluded. The qualified specimens were placed in a curing box for 28 days and subsequently taken out for the loading test.

2.2. Test Equipment and Loading. The TZW-500 microprocessor-controlled electro-hydraulic servo rock direct shear apparatus was used as the loading equipment in this test. The load-controlled loading mode was applied in the normal direction; specifically, axial compression (loading rate: $100 \mathrm{~N} / \mathrm{s}$ ) was applied through the axial loading system of this apparatus until the preset axial compression $(10 \mathrm{KN})$ was reached. The displacement-controlled loading mode was applied in the tangential direction at a loading rate of $0.01 \mathrm{~mm} / \mathrm{s}$ until the specimen experienced compression failure, as shown in Figure 3. The mean value of six groups of test results was adopted to reduce the test errors. Under similar conditions, the mean values of the peak shear strength, postpeak residual strength, cohesion, and internal friction angle of the six intact rock-like specimens were measured to be $8.0 \mathrm{MPa}, 2.4 \mathrm{MPa}, 6.58$, and $48.5^{\circ}$, respectively.

A uniaxial compression test was conducted on the intact rock-like specimens by using the RMT rock mechanic test system, and the average uniaxial compressive strength was obtained as $42.0 \mathrm{MPa}$. The physical and mechanical parameter values of the intact rock-like specimens were acquired after the test and are shown in Table 1. 


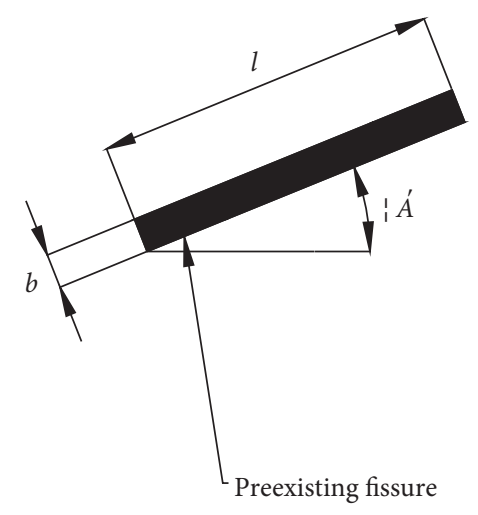

FIGURE 2: Dimensional drawing of the specimens and prefabricated joints.

\section{Result Analysis}

\subsection{Strength Characteristics of Rock-Like Specimens with Prefabricated Fissures}

3.1.1. Relationship between Peak Shear Strength of Each Specimen and Dip Angle of the Prefabricated Fissure. On the basis of the test results, the change curve of the peak shear strength of the rock-like specimens with dip angle $\alpha$ of the prefabricated fissure was plotted and is shown in Figure 4. The following observations were made:

(1) With the increase in dip angle $\alpha$ of the prefabricated fissure, the peak shear strength of the prefabricated, fissure-containing, rock-like specimens initially decreased, then increased, and the peak shear strength curve presented a similar " $U$ " shape. At a dip angle of $\alpha \in\left[30^{\circ}, 60^{\circ}\right]$, the peak shear stress was within the peak-valley interval; the minimum peak shear strength in the peak valley of each curve accounted for $43 \%-64 \%$ of the peak shear strength of the specimen not containing any prefabricated fissure.

(2) The peak shear strength of the prefabricated fissurecontaining specimens was large at $\alpha \in\left[0^{\circ}, 30^{\circ}\right)$ or $\alpha \in\left(60^{\circ}, 90^{\circ}\right]$.

(3) The peak shear strength of all specimens reached the maximum value at dip angle $\alpha=90^{\circ}$ and different lengths $l$ and widths $b$ of the prefabricated fissure. The maximum peak shear strength on each curve accounted for $63 \%-79 \%$ of the peak shear strength of the specimen without a prefabricated fissure.

The test results indicated that the peak shear strengths of all prefabricated, fissure-containing, rock-like specimens were lower than the peak biaxial shear strength of the intact specimens. This result shows that the joint fissures existing inside the rock-like specimens exerted different deterioration effects on the specimens, and the dip angle of a fissure had a considerable influence on specimen deterioration.

3.1.2. Relationship between Peak Shear Strength of Specimens and Width of the Prefabricated Fissure. On the basis of the test results, the change curve of the peak strength of the rock- like specimens with width $b$ of the prefabricated fissure was plotted and is shown in Figure 5. The following observations were obtained:

(1) As the width $b$ of the prefabricated fissure increased, the peak shear strength of the specimens was decreased, but the reduction amplitude gradually slowed down, indicating that with the increase in width $b$ of the prefabricated fissure, the deteriorating effect on the shear strength of the rock-like specimens was gradually reduced.

(2) At $l=20$ and $30 \mathrm{~mm}$ and $\alpha \in\left[30^{\circ}, 60^{\circ}\right]$, the peak shear strengths of the specimens with the same dip angle of the fissure were approximate, indicating that at a fixed dip angle $\alpha$ and fissure length of $l \geq 20 \mathrm{~mm}$, the correlation between peak shear strength and fissure width $b$ was low.

(3) The ratios of the peak shear strength of the prefabricated fissure-containing specimens to that of the fissure-free specimens were compared. The ratios were approximate at the same dip angle $\alpha$ and different fissure widths $b$. This result shows that at the same dip angle $\alpha$, fissure width $b$ had a minor influence on the peak strength of the specimens.

According to the analysis, fissure width $b$ influenced the peak strength of the rock-like specimens with prefabricated fissures to different degrees, and different fissure widths exhibited different influence degrees. The influence degree of fissure width $b$ on the peak shear strength of the rock-like specimens containing prefabricated fissures was smaller than that of fissure dip angle $\alpha$.

3.1.3. Relationship between Peak Shear Strength of Specimens and Length of the Prefabricated Fissure. On the basis of the test results, the change curve of the peak strength of the rocklike specimens with length $l$ of the prefabricated fissure was plotted and is shown in Figure 6. The following observations were obtained:

(1) At the same dip angle $\alpha$ of the prefabricated fissure, the peak shear strength of each specimen was gradually reduced with the increase in length $l$ of the prefabricated fissure.

(2) The curve in the figure was divided into two parts. In the first part, fissure length $l$ increased from $10 \mathrm{~mm}$ to $20 \mathrm{~mm}$, and this curve segment had a steep slope. In the second part, fissure length $l$ was increased from $20 \mathrm{~mm}$ to $30 \mathrm{~mm}$, and this segment had a gentle slope, indicating that after fissure length $l$ exceeded a limiting value (e.g., $l \geq 20 \mathrm{~mm}$ ), the influence degree of increasing fissure length $l$ on the peak shear strength of specimens gradually weakened.

\subsection{Crack Coalescence and Propagation Modes of Rock-Like Specimens with Prefabricated Fissures}

3.2.1. Crack Coalescence and Propagation Modes. In a biaxial shear condition, the crack propagation mode after specimen 


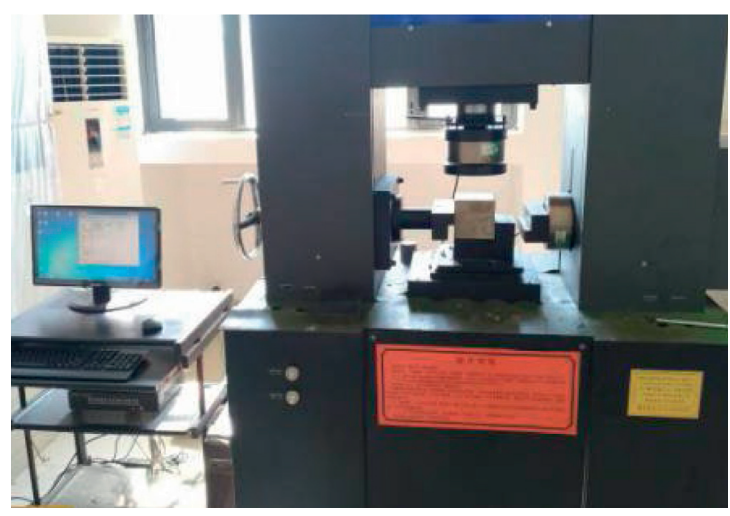

(a)

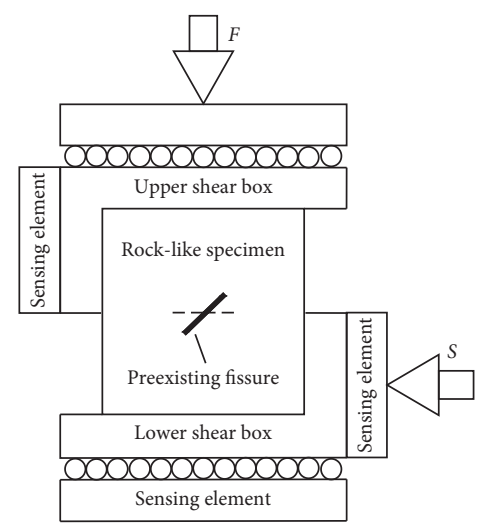

(b)

FIGURE 3: eal biaxial shear loading photo and biaxial loading diagram.

TABLE 1: Comparison of physical and mechanical parameters between original rock and rock-like specimens.

\begin{tabular}{|c|c|c|c|c|c|c|}
\hline Mechanical parameters & $\gamma\left(\mathrm{kN} / \mathrm{m}^{3}\right)$ & $\sigma_{c}(\mathrm{MPa})$ & $E(\mathrm{GPa})$ & $\mu$ & $C(\mathrm{MPa})$ & $\varphi\left({ }^{\circ}\right)$ \\
\hline Sandstone [27] & 23 & $20-170$ & $4.9-78.5$ & $0.02-0.2$ & - & - \\
\hline Rock-like specimens & 25.3 & $41.0-43.0$ & $3.16-3.56$ & 0.3 & $5.98-7.18$ & $45.5-51.5$ \\
\hline
\end{tabular}

loading was affected by the dip angle, length, and width of the prefabricated fissure. After the biaxial loading process, the generated cracks mainly included shear, secondary shear, secondary tensile, and secondary tensile-shear cracks, as shown in Figure 7(a). Shear crack was the main crack and was surely generated; the other cracks were secondary and generated with the shear crack, and they appeared solely or in a group. As shown in Figure 7(b), the crack propagation and coalescence modes were mainly divided into four types:

(1) At a small dip angle $\alpha$ of the prefabricated fissure, only a single main shear crack was generated in the specimen, and it formed a coalescence with the prefabricated fissure.

(2) When the dip angle $\alpha$ of the prefabricated fissure increased, the main shear crack initially propagated at the two ends of the prefabricated fissure after loading. When the shear displacement was increased to a certain degree, the secondary tensile-shear crack was formed, and it was approximately parallel to the main shear crack.

(3) With the increase in dip angle $\alpha$ of the prefabricated fissure, the main shear crack initially propagated at the two ends of the prefabricated fissure. Then, a secondary shear crack was generated. The main shear crack and secondary shear crack appeared in a conjugate manner.

(4) At a large dip angle $\alpha$ of the prefabricated fissure, the main shear crack was generated only at one end of the prefabricated fissure, or one main shear crack was generated at the middle of the prefabricated fissure, whereas the other was generated at the end of the prefabricated fissure accompanied with the secondary tensile crack.

\subsubsection{Influence of the Dip Angle of the Prefabricated Fissure} on Crack Coalescence and Propagation Mode

(1) As shown in Figure 8(a), the main crack of the prefabricated fissure-containing specimens was shear crack, and shear cracks developed along the shearing surface and presented an approximately horizontal distribution. Their included angle with the horizontal plane was generally smaller than $13^{\circ}$. One end of the shearing surface was usually accompanied with the generation of secondary tensile cracks.

(2) Figure 8(b) indicates that when the dip angle of the prefabricated fissure was $\alpha \in\left[0^{\circ}, 10^{\circ}\right]$, the main crack was shear crack, which began from the two tip ends of the prefabricated fissure. As the shear stress increased, the shear cracks gradually propagated toward the two sides. With the increase in shear displacement, secondary tensile cracks developed and propagated at the two sides of the shearing surface due to the interlocking effect of the shearing surface. The shear strength reached the peak value. With the further propagation of shear and tensile cracks, the shear cracks at two sides of the prefabricated fissure showed a coalescence trend, the shear stress decreased sharply, and residual shear stress was generated due to the interlocking effect of the shearing surface. In general, coalescence did not occur between secondary tensile cracks; instead, several secondary tensile cracks ran through shear cracks. The shear cracks were approximately distributed in the horizontal direction, and their included angle with the prefabricated fissure was generally smaller than $13^{\circ}$. The secondary tensile 


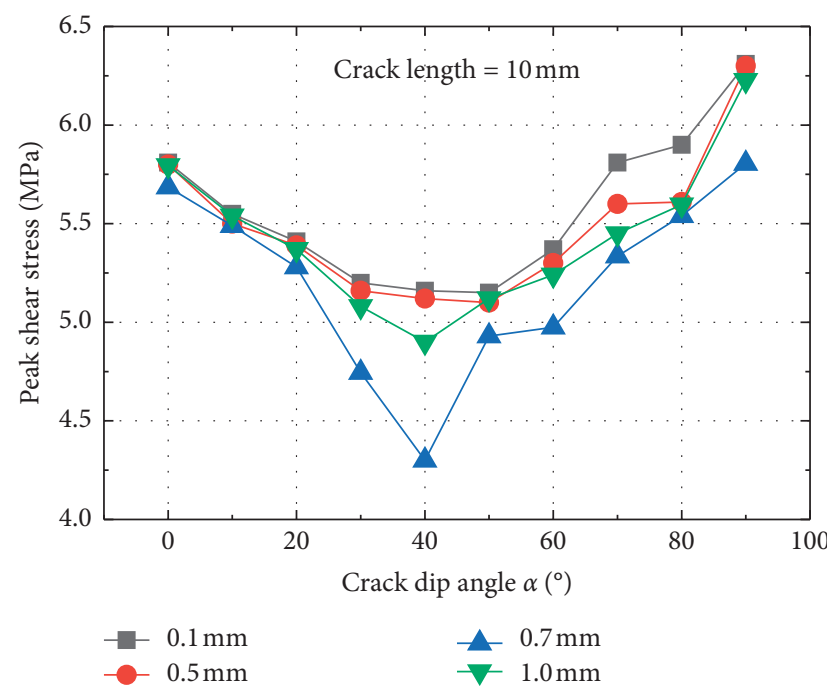

(a)

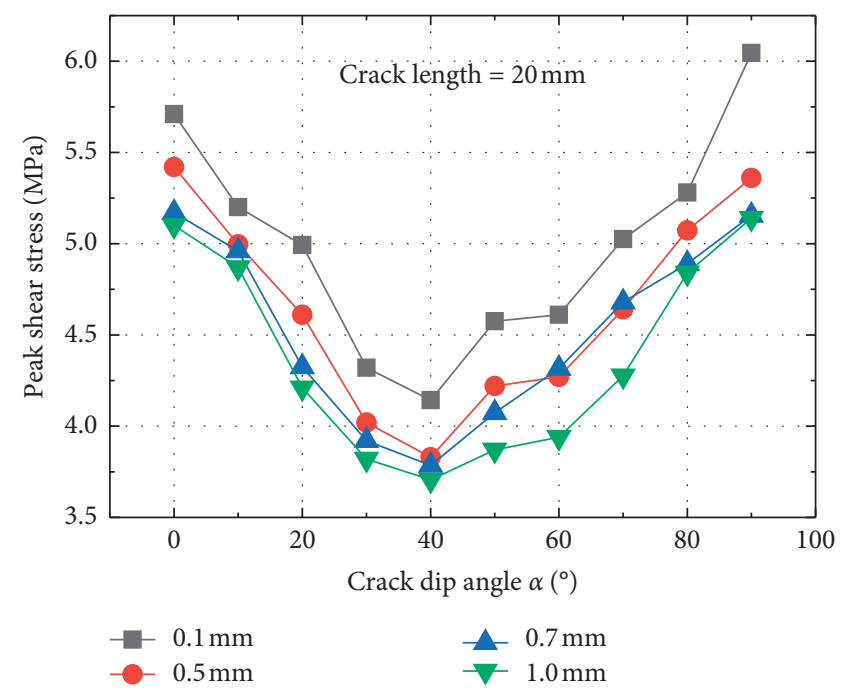

(b)

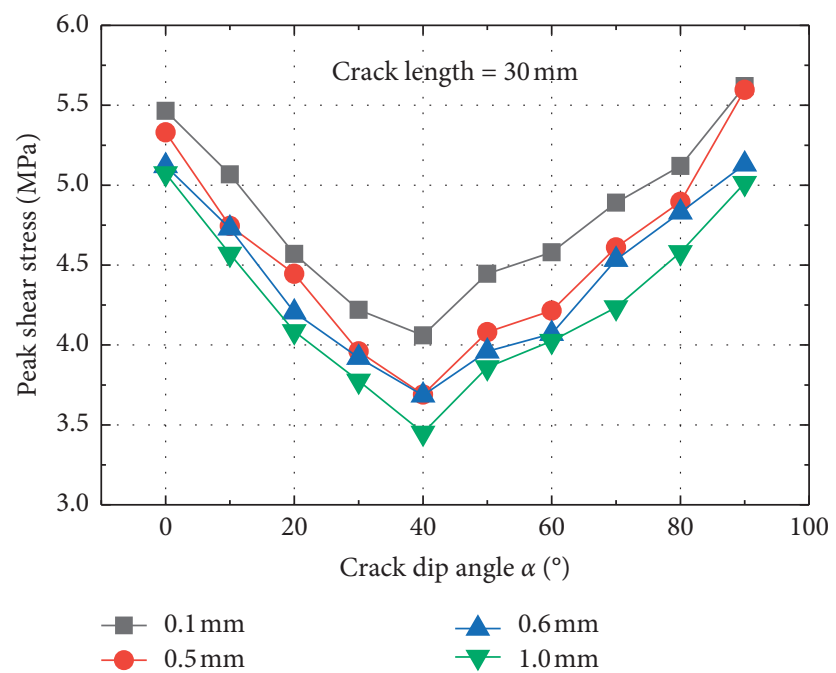

(c)

FIgURE 4: Relation curve between prefabricated fissures with different dip angles and peak shear strength of specimens.

cracks generally developed at one end of the prefabricated fissure. The propagation direction of the secondary tensile-shear cracks not running through the shear cracks was nearly parallel to that of the main shear crack, and that of the secondary tensile cracks running through the shear cracks generally had an included angle of $55^{\circ}-75^{\circ}$ with the main shear crack.

(3) As shown in Figures 8(c) and 8(d), with the increase in the dip angle of the prefabricated fissure $\left(\alpha \in\left(10^{\circ}\right.\right.$, $\left.50^{\circ}\right)$ ), the initial propagation angle $\beta_{1}$ between the main shear crack and prefabricated fissure was generally smaller than $13^{\circ}$, and the initial propagation length of the main shear crack was small (1/5-1/ 3 of fissure length $l$ ). With the increase in shear displacement, the main shear crack gradually propagated in a bending manner toward the two sides, and the included angle $\beta_{2}$ between the main shear crack and prefabricated fissure increased to within $30^{\circ}-70^{\circ}$. The main shear crack and prefabricated fissure experienced mutual coalescence. The secondary tensile-shear crack was approximately parallel to the main shear crack and did not run through the main shear crack; if coalescence did happen, it would have occurred at the initial position of the shear crack. With the propagation of the main shear crack, secondary tensile cracks were generated, they did not run through the main shear crack. Their propagation direction had an included angle of smaller than $45^{\circ}$ with the main shear crack.

(4) As indicated in Figures $8(\mathrm{e})$ and $8(\mathrm{f})$, at $\alpha \in\left[50^{\circ}, 70^{\circ}\right)$, the main crack was shear crack, which initiated at the two tip ends of the prefabricated fissure. The included angle $\beta_{2}$ between the main shear crack and prefabricated fissure increased with the increase in $\alpha$ (within $32^{\circ}-80^{\circ}$ ) accompanied with the appearance 

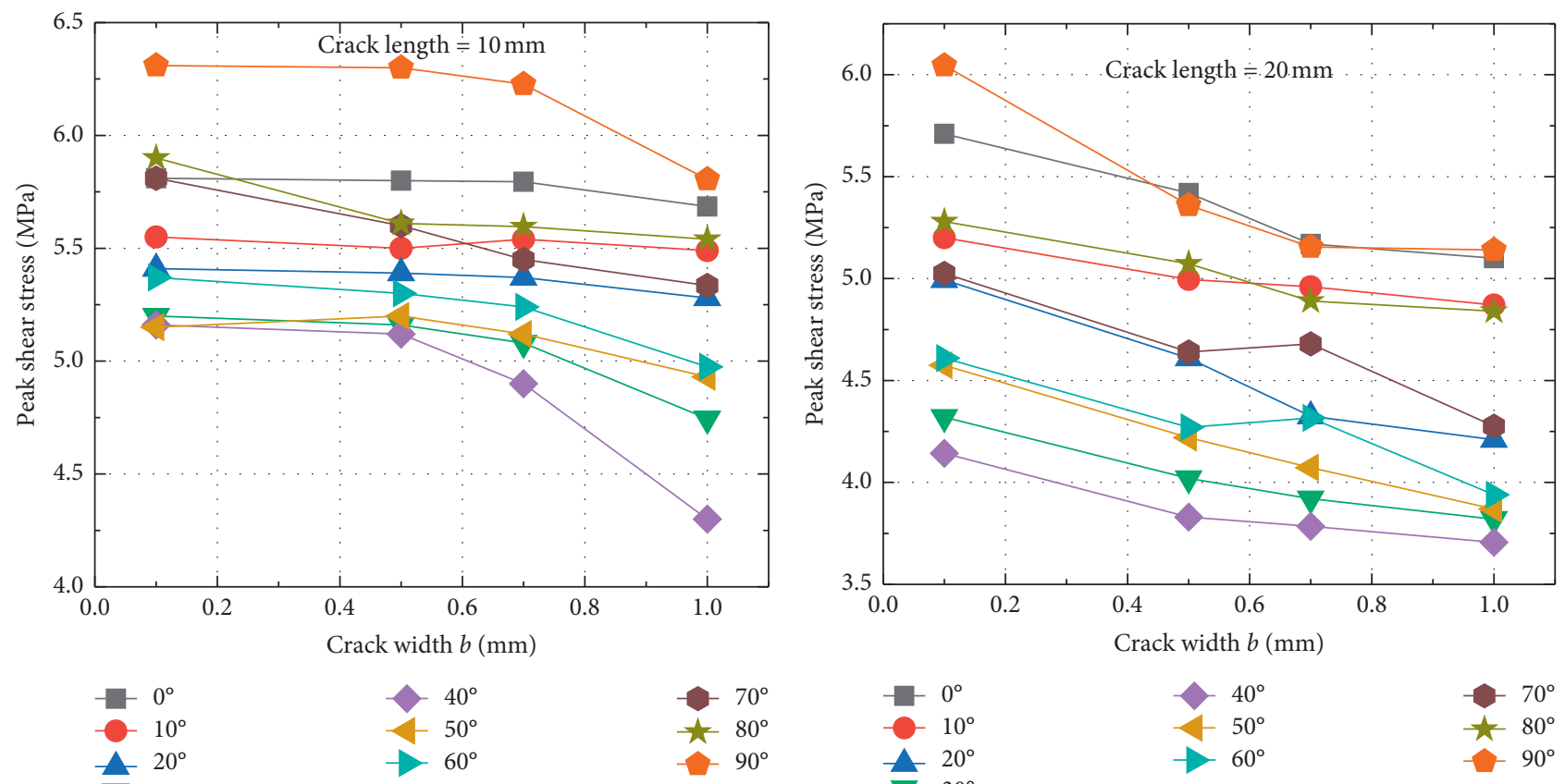

(a)

(b)

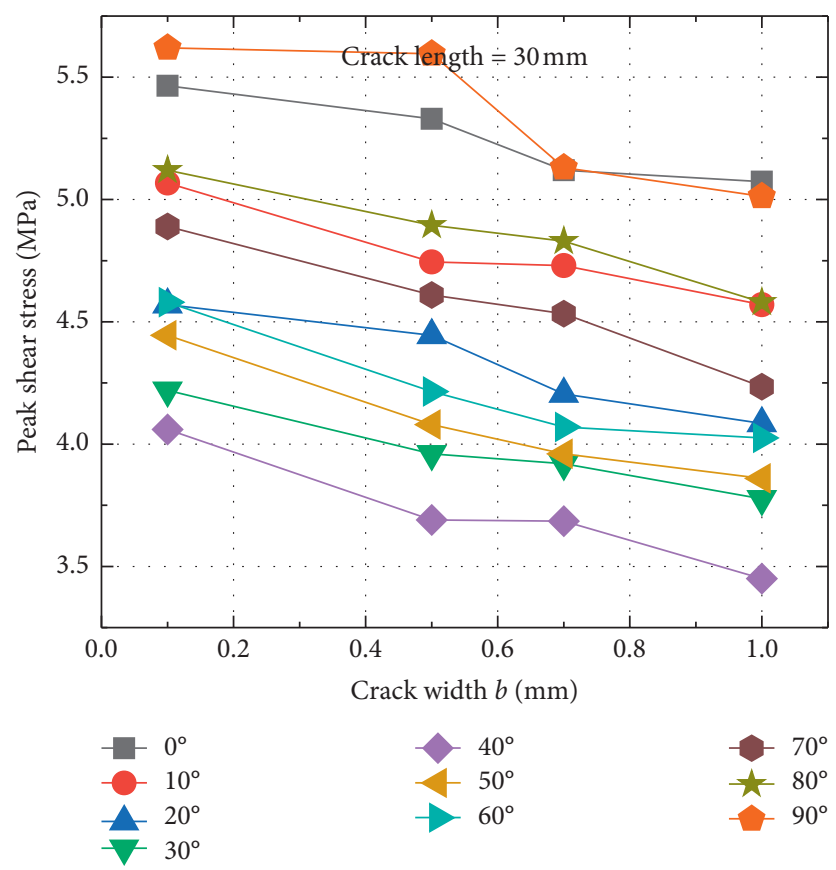

(c)

FIgURE 5: Relation curve between prefabricated fissures with different widths and peak shear strength of specimens.

of secondary shear cracks, which generally propagated from the two tip ends of the prefabricated fissure. The included angle between the secondary shear cracks and prefabricated fissure ranged from $40^{\circ}$ to $60^{\circ}$.
(5) As shown in Figures $8(\mathrm{~g})$ and $8(\mathrm{~h})$, at $\alpha \in\left[70^{\circ}, 90^{\circ}\right]$, the main shear crack propagated at one end of the prefabricated fissure, or one main shear crack propagated at one end of the prefabricated fissure, whereas the other one propagated at one position in the middle of 


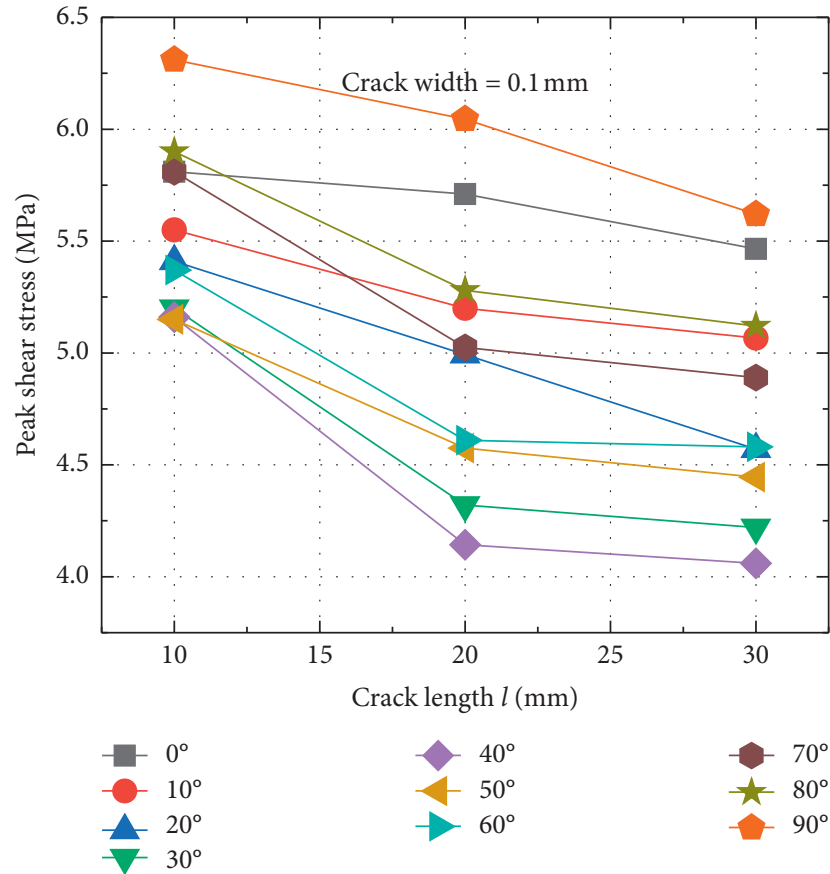

(a)

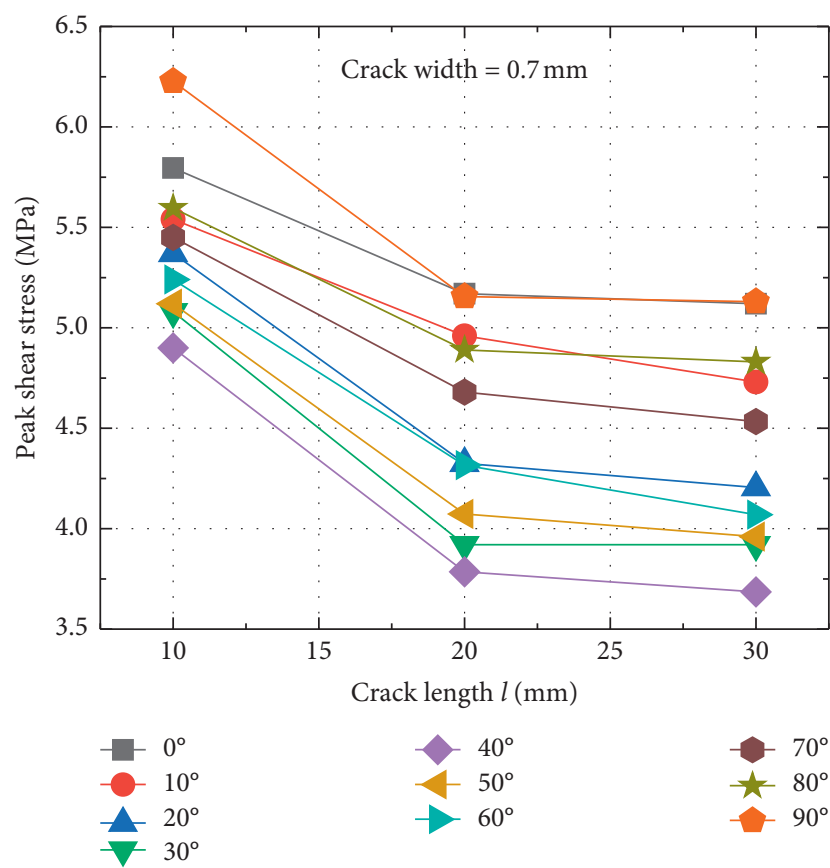

(c)

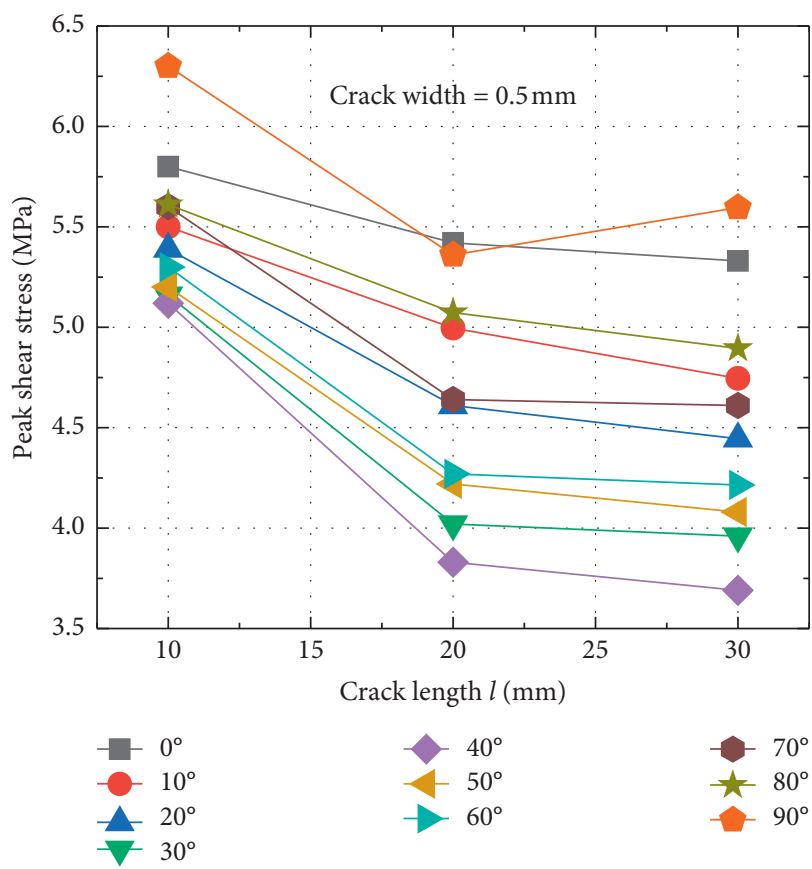

(b)

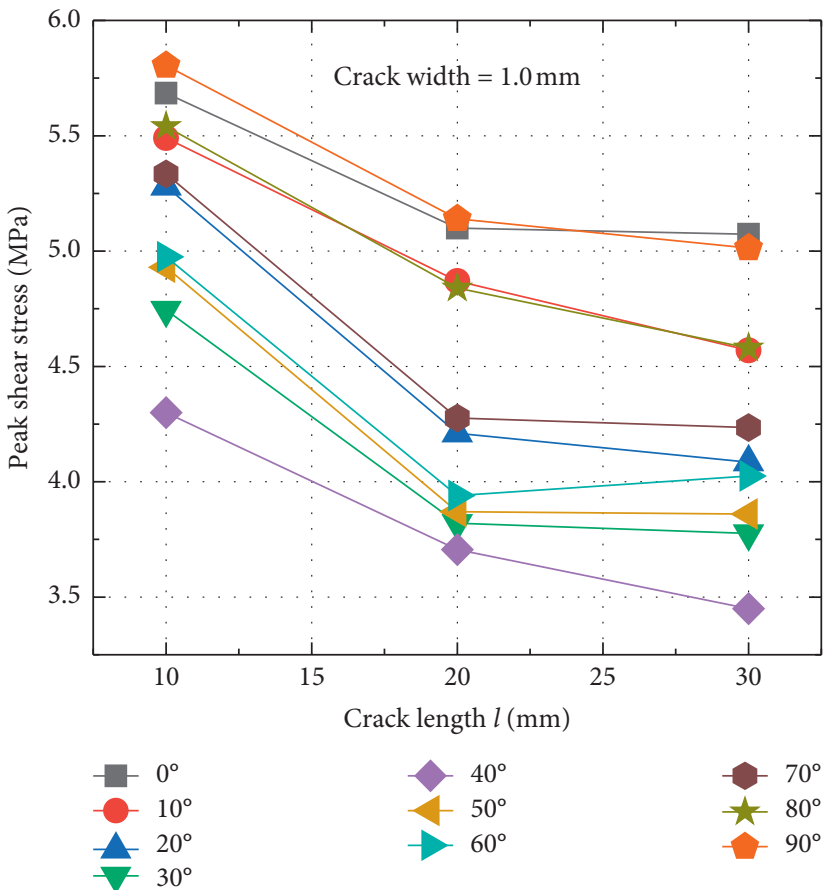

(d)

FigURE 6: Relation curve between prefabricated fissures with different lengths and peak shear strength of specimens.

the prefabricated fissure. The included angle $\beta_{2}$ between the main shear crack and prefabricated fissure was $55^{\circ}-90^{\circ}$. The secondary tensile-shear cracks propagated together with the main shear crack, and they were generally approximately parallel to the shear cracks. At the two sides of the shear cracks, secondary tensile cracks were developed, and several of them showed a coalescence trend with the shear cracks.
(6) At $\alpha \in\left[0^{\circ}, 20^{\circ}\right) \cup\left(70^{\circ}, 90^{\circ}\right]$, the shear stress needed by the loading-induced specimen failure was large, the crack propagation was slow, the shear cracks mostly propagated at one end of the prefabricated fissure, and the cracks that propagated were mainly shear cracks. As the shear displacement increased, secondary tensile cracks were developed until the specimen failed. When $\alpha \in\left(30^{\circ}, 50^{\circ}\right)$, the shear stress 


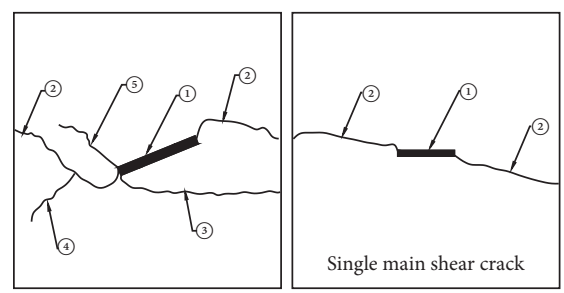

(1) Prefabricated fissure

(2) Shear crack

(3) Secondary shear crack

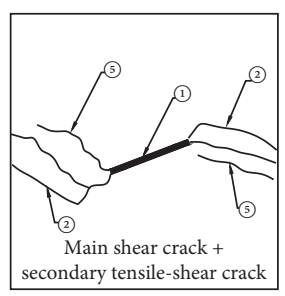

(1) Prefabricated fissure

(2) Shear crack

(3) Secondary shear crack

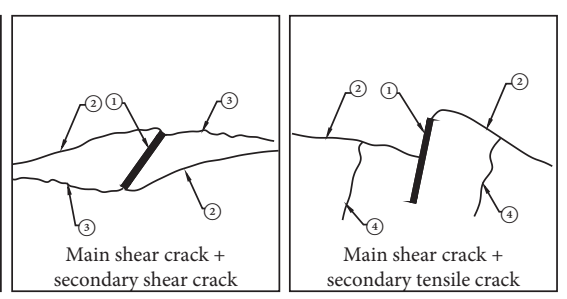

(4) Secondary tensile crack

(5) Secondary tensile-shear crack

(a)

(b)

FIGURE 7: Schematic of crack types and propagation modes. (a) Crack type. (b) Crack propagation mode. Note: (1) prefabricated fissure; (2) shear crack; (3) secondary shear crack; (4) secondary tensile crack; (5) secondary tensile-shear crack.

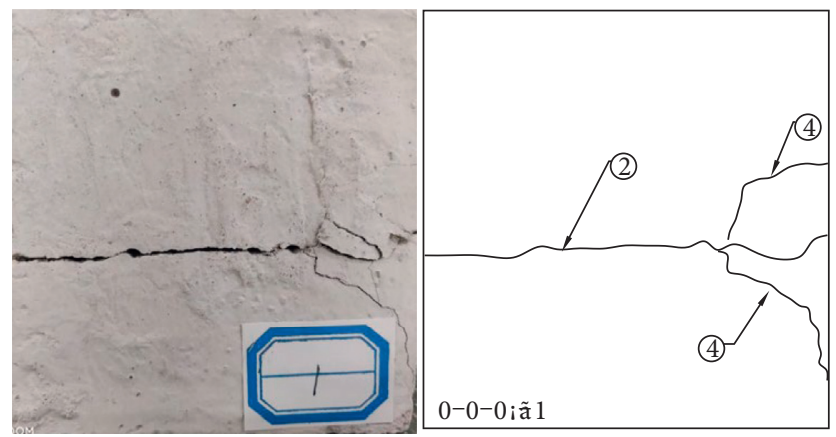

(a)
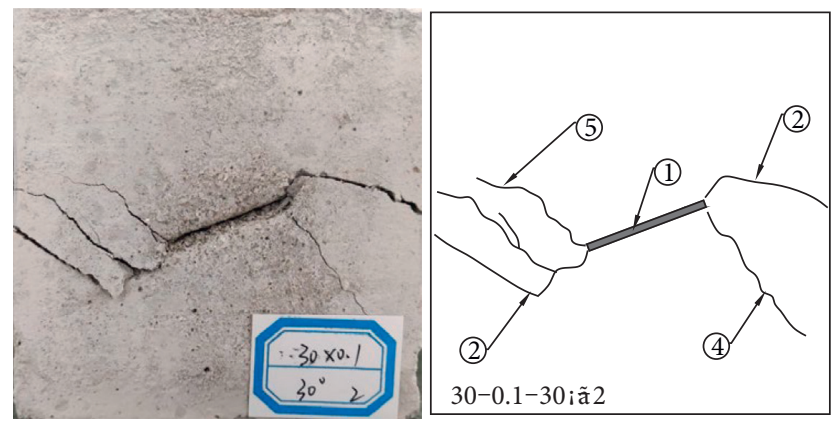

(c)
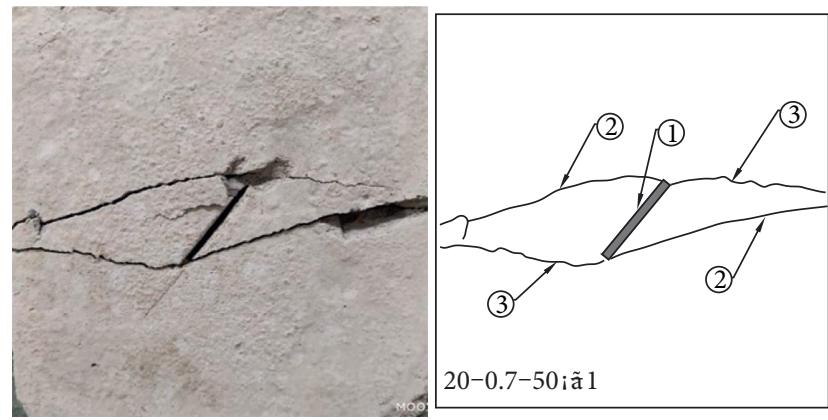

(e)
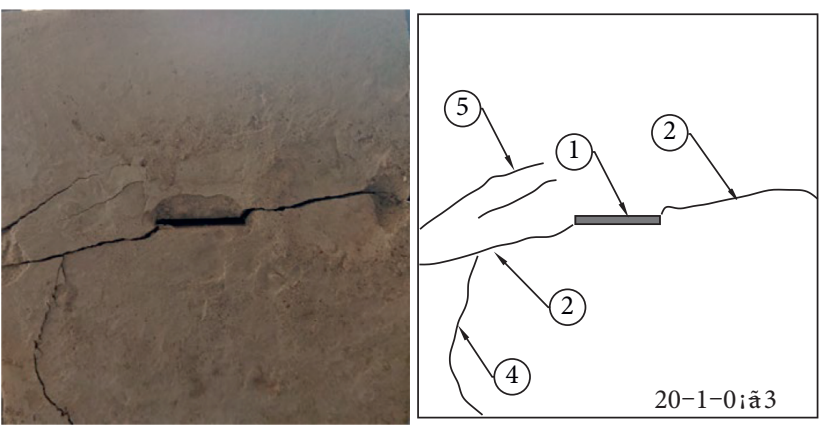

(b)
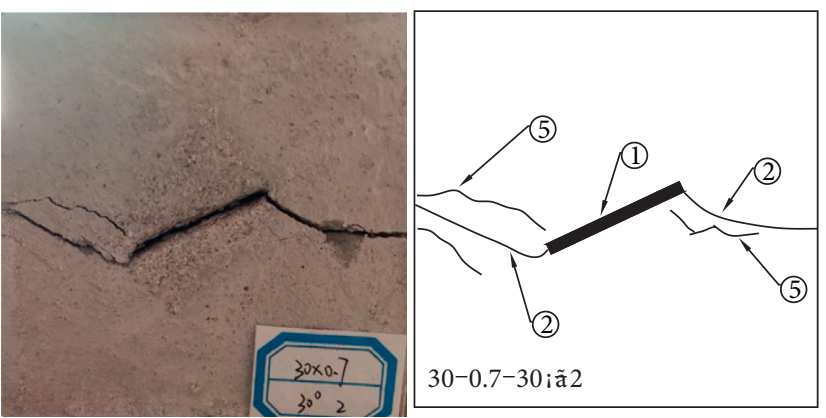

(d)
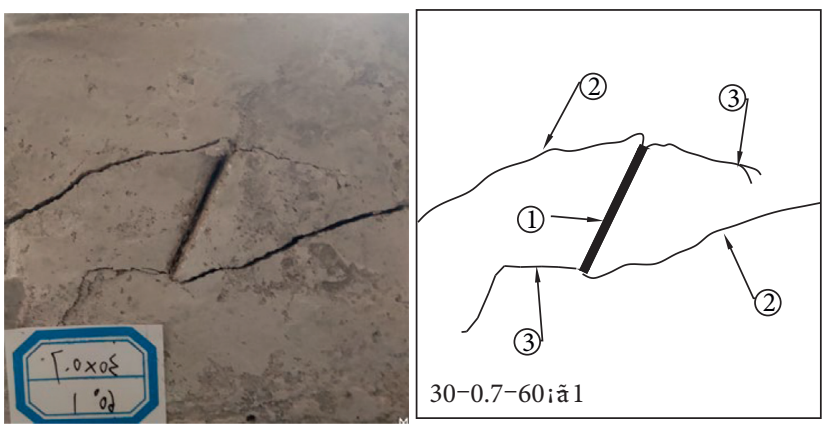

(f)

FIgURe 8: Continued. 

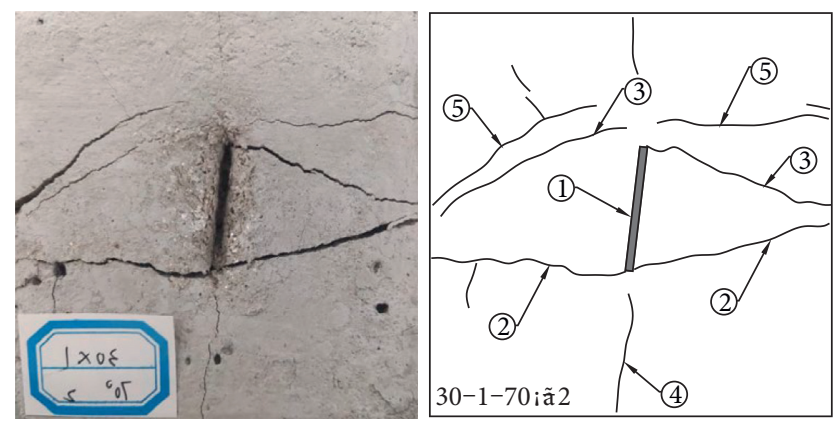

(g)
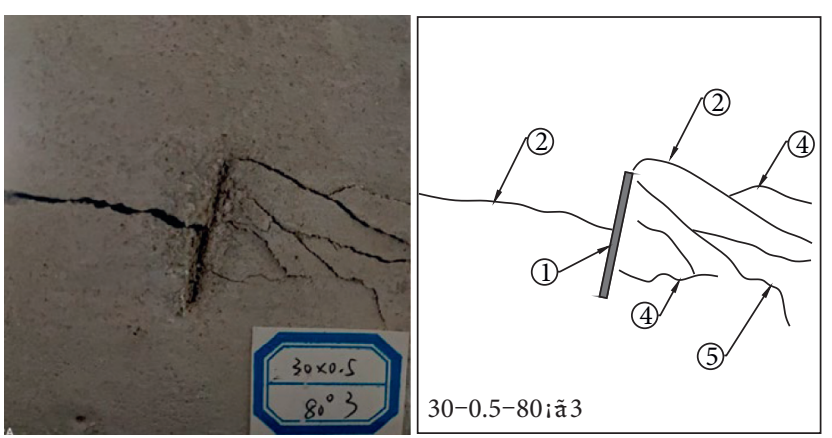

(h)

FiguRE 8: Test results on the dip angle of the prefabricated fissure and crack coalescence mode. Note: (1) prefabricated fissure; (2) shear crack; (3) secondary shear crack; (4) secondary tensile crack; (5) secondary tensile-shear crack.

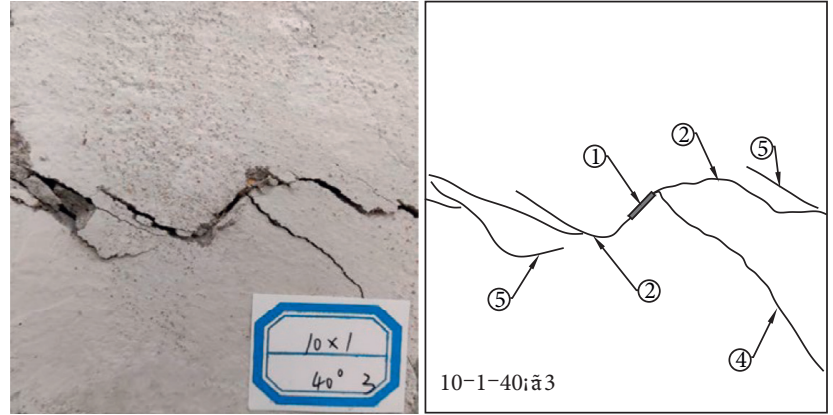

(a)

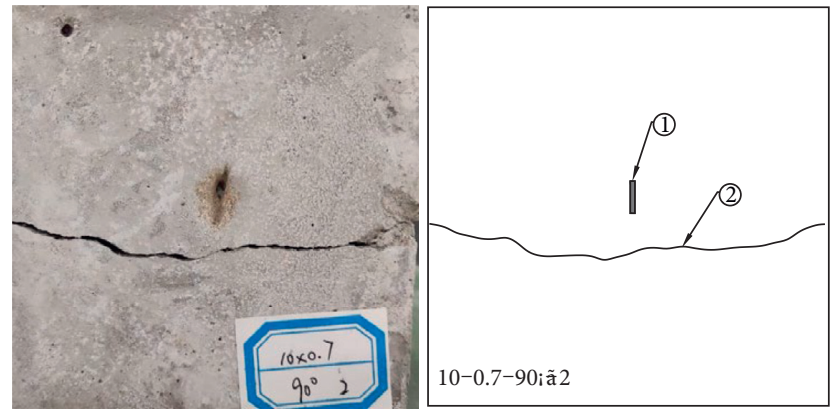

(c)
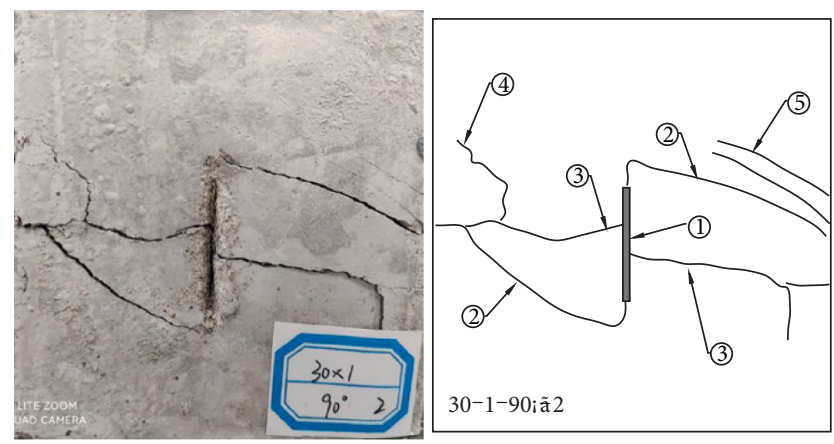

(e)
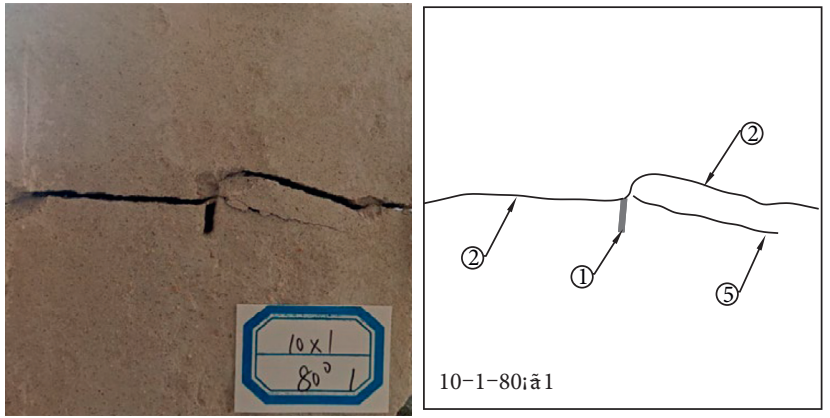

(b)
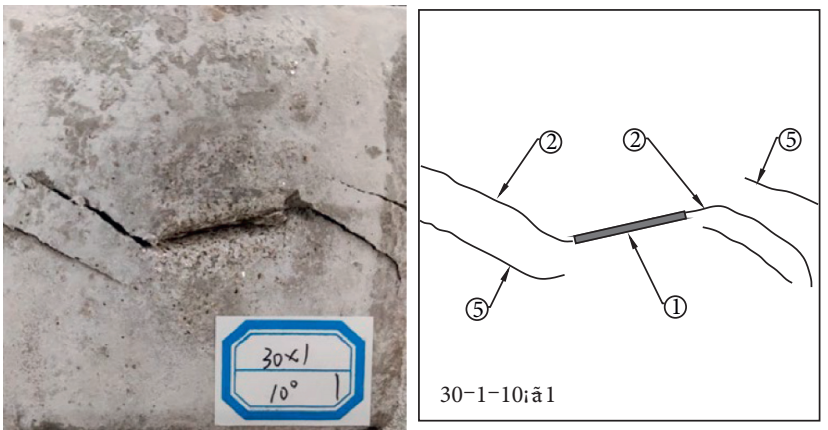

(d)
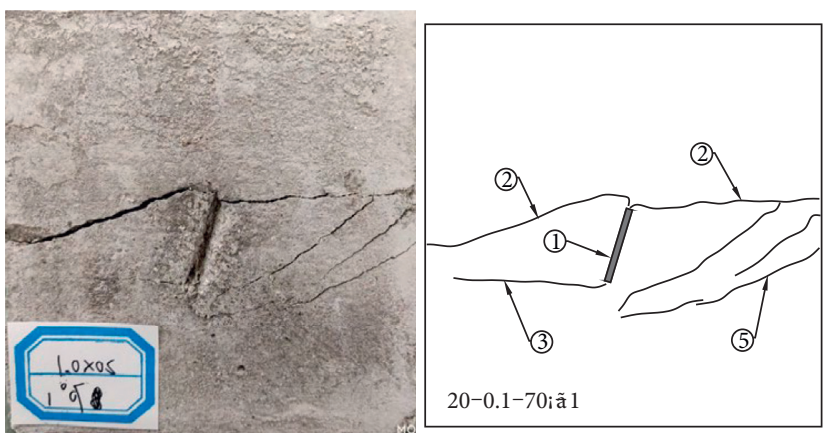

(f)

Figure 9: Test results on the length of the prefabricated fissure and crack coalescence mode. Note: (1) prefabricated fissure; (2) shear crack; (3) secondary shear crack; (4) secondary tensile crack; (5) secondary tensile-shear crack. 
needed by the loading-induced specimen failure was small, the crack propagation was fast, and the cracks were generated under tensile-shear joint action.

\subsubsection{Influence of Prefabricated Fissure Length on Crack Coalescence and Propagation Mode}

(1) At $l \leq 10 \mathrm{~mm}$,

(1) When $\alpha \in\left[0^{\circ}, 40^{\circ}\right]$, the main crack usually propagated along the two tip ends of the prefabricated fissure accompanied with the development and propagation of secondary tensile-shear and secondary tensile cracks, as shown in Figure 9(a).

(2) When $\alpha \in\left[70^{\circ}, 90^{\circ}\right]$, the main shear crack developed only along one end of the prefabricated fissure together with tensile-shear cracks, as shown in Figure 9(b), or the main shear crack was generated at one side of the prefabricated fissure and did not pass through the end part of the prefabricated fissure, presenting a linear distribution, namely, the main shear crack propagated only along the direction of shear stress, as seen in Figure 9(c).

(2) At $l \geq 20 \mathrm{~mm}$,

(1) When $\alpha \in\left[0^{\circ}, 40^{\circ}\right]$, the main shear cracks propagated at the two tip ends of the prefabricated fissure and were mainly shear cracks, accompanied with the development and propagation of secondary tensile-shear cracks, which were approximately parallel to the main shear cracks, as shown in Figures 8(c) and 9(d).

(2) When $\alpha \in\left[70^{\circ}, 90^{\circ}\right]$, the main shear cracks propagated at the two ends or one end of the prefabricated fissure, and their included angle $\beta_{2}$ with the prefabricated fissure was $55^{\circ}-90^{\circ}$. With the increase in shear displacement, secondary shear cracks were generated, and they were approximately perpendicular to the prefabricated fissure, as shown in Figure 9(e). When the main shear cracks propagated at the two ends of the prefabricated fissure, the secondary tensile-shear cracks were approximately parallel to the main shear cracks. When the shear cracks propagated at one end of the prefabricated fissure, the included angle between secondary tensile-shear and shear cracks was generally smaller than $40^{\circ}$, as shown in Figures 8(g) and 9(f).

(3) With the increase in length $l$ of the prefabricated fissure, the shear strength of the different specimens was reduced, and the crack propagation mode was obviously changed.

\section{Conclusions}

Cubic rock-like specimens containing a single fissure were prefabricated to conduct a biaxial shear test, and their strength characteristics, crack coalescence, and propagation modes were explored under different geometric conditions. The following main conclusions were derived:

(1) When the dip angle $\alpha$ of the prefabricated fissure increased, the peak shear strength of the rock-like specimens decreased initially, then increased, and the peak shear strength curve presented a similar " $U$ " shape. At $\alpha \in\left[30^{\circ}, 60^{\circ}\right]$, the peak shear strength was in the peak-valley interval; the minimum peak shear strength of each curve accounted for $43 \%-64 \%$ of the peak shear strength of the intact specimen. At $\alpha=90^{\circ}$ and different lengths $l$ and widths $b$ of the prefabricated fissure, the peak shear strengths of all specimens reached the maximum values. The maximum shear strength of each curve accounted for $63 \%-79 \%$ of the peak shear strength of the intact specimen.

(2) With the increase in the width $b$ of the prefabricated fissure, the peak shear strength of the specimens decreased, but the reduction amplitude gradually slowed down. At $l \geq 20 \mathrm{~mm}$, the same dip angle $\alpha$, and different fissure widths $b$, the correlation degree between peak shear strength and fissure width $b$ was low.

(3) When the length $l$ of the prefabricated fissure increased, the peak shear strength of the specimens was gradually reduced. At $l<20 \mathrm{~mm}$, the change in fissure length $l$ had a great influence on the peak shear strength. When $l \geq 20 \mathrm{~mm}$, the length $l$ of the prefabricated fissure exerted a minor influence on the peak shear strength. The influence degree of fissure width on the peak strength of the rock-like specimens with a prefabricated fissure was lower than that of dip angle $\alpha$ and length $l$.

(4) The crack coalescence, propagation modes, and characteristics of the rock-like specimens with prefabricated fissures after the loading process were analyzed. The crack coalescence mode was divided into four types: (1) single main shear coalescence mode, (2) main shear crack coalescence and secondary tensile-shear crack propagation mode, (3) main shear crack coalescence and secondary shear crack propagation mode, and (4)main shear crack coalescence and secondary tensile crack propagation mode.

(5) The relationships of the crack propagation modes of the rock-like specimens with dip angle $\alpha$ and length $l$ of the prefabricated fissure were determined. At $\alpha \in\left[0^{\circ}, 20^{\circ}\right) \cup\left(70^{\circ}, 90^{\circ}\right]$, the shear stress needed by postloading specimen failure was large, the crack propagation was low, most shear cracks propagated at one end of the prefabricated fissure, and the crack propagation occurred mainly under shear action. At $\alpha \in\left(30^{\circ}, 50^{\circ}\right)$, the shear stress needed by postloading specimen failure was small, and the crack propagation was fast under tensileshear joint action. 
Notably, due to restrictions in paper length, the effects of prefabricated fissure spacing on specimen strength and crack propagation mode were not considered in this study. Moreover, the quantitative relationships of specimen peak strength with the dip angle, length, and width of prefabricated fissures were not explored. These issues will be discussed in a follow-up study.

\section{Data Availability}

All the data in this paper are from laboratory experiments, which have not been applied in other journals. The data used in this research paper can be found in the supplementary file.

\section{Conflicts of Interest}

The authors declare that there are no conflicts of interest.

\section{Acknowledgments}

This paper was funded by Anhui Natural Science Research Program of Universities and Colleges (No. KJ2018A0073) and Science and Technology Program of Key Major Safety Production Accident Prevention and Control Technology (No. anhui-0004-2017AQ).

\section{Supplementary Materials}

The supplementary file includes the test results of some precast fractured rock-like specimens as shown in Figures 1 and 2. The summary test results are listed in Table 1. (Supplementary Materials)

\section{References}

[1] M. F. Ashby and S. D. Hallam, "The failure of brittle solids containing small cracks under compressive stress states," Acta Metallurgica, vol. 34, no. 3, pp. 497-510, 1986.

[2] C. G. Sammis and M. F. Ashby, "The failure of brittle porous solids under compressive stress states," Acta Metallurgica, vol. 34, no. 3, pp. 511-526, 1986.

[3] A. Bobet, "The initiation of secondary cracks in compression," Engineering Fracture Mechanics, vol. 66, no. 2, pp. 187-219, 2000.

[4] M. Cai, P. K. Kaiser, Y. Tasaka, T. Maejima, H. Morioka, and M. Minami, "Generalized crack initiation and crack damage stress thresholds of brittle rock masses near underground excavations," International Journal of Rock Mechanics and Mining Sciences, vol. 41, no. 5, pp. 833-847, 2004.

[5] R. H. C. Wong, P. Lin, C. A. Tang et al., "Mechanisms of crack coalescence of pre-existing flaws under biaxial compression," Chinese Journal of Rock Mechanics and Engineering, vol. 21, no. 6, pp. 808-816, 2002.

[6] M. Sagong and A. Bobet, "Coalescence of multiple flaws in a rock-model material in uniaxial compression," International Journal of Rock Mechanics and Mining Sciences, vol. 39, no. 2, pp. 229-241, 2002.

[7] A. Bobet and H. H. Einstein, "Fracture coalescence in rocktype materials under uniaxial and biaxial compression," International Journal of Rock Mechanics and Mining Sciences, vol. 35, no. 7, pp. 863-888, 1998.
[8] P. Zhang, N. Li, R. He, and J. Xu, "Mechanism of fracture coalescence between two pre-existing flaws under dynamic loading," Chinese Journal of Rock Mechanics and Engineering, vol. 25, no. 6, pp. 1210-1217, 2006.

[9] S. Yang, Y. Dai, L. Han, and Y. He, "Uniaxial compression experimental research on deformation and failure properties of brittle marble specimen with pre-existing fissures," Chinese Journal of Rock Mechanics and Engineering, vol. 28, no. 12, pp. 2391-2404, 2009.

[10] C. Ping, H. Liwen, and T. Guodong, "Experimental study on failure characteristics of jointed rock mass under staged unloading conditions," Journal of Vibroengineering, vol. 21, no. 4, pp. 927-939, 2019.

[11] M. Yu, G. Xu, G. Tang et al., "Experimental study on stepped unloading of rock-like materials with pre-existing fissure," Chinese Journal of Underground Space and Engineering, vol. 16, no. 6, pp. 1672-1681, 2020.

[12] S. Teng, S. Yang, Y. Huang, and W. Tian, "Experimental study of influence of crack filling on mechanical properties of Brazilian discs," Rock and Soil Mechanics, vol. 39, no. 12, pp. 4493-4507-4516, 2018.

[13] W. Tian, S. Yang, and P. Yin, "Strength and crack coalescence behavior of sandstone containing four filled or unfilled preexisting fissures," Journal of Basic Science and Engineering, vol. 26, no. 5, pp. 1005-1015, 2018.

[14] C. Tang, "Numerical simulation of progressive rock failure and associated seismicity," International Journal of Rock Mechanics and Mining Sciences, vol. 34, no. 2, pp. 249-261, 1997.

[15] C. A. Tang and S. Q. Kou, "Crack propagation and coalescence in brittle materials under compression," Engineering Fracture Mechanics, vol. 61, no. 3, pp. 311-324, 1998.

[16] Y. Wang, Y. Miao, and Y. Li, "Numerical simulation of the experiment on rock with preexisted cracks under compression and shearing," Chinese Journal of Rock Mechanics and Engineering, vol. 23, no. 18, pp. 3113-3116, 2004.

[17] K. Luo, G. Zhao, J. Zeng, X. Zhang, and C. Pu, "Fracture experiments and numerical simulation of cracked body in rock-like materials affected by loading rate," Chinese Journal of Rock Mechanics and Engineering, vol. 37, no. 8, pp. 1833$1842,2018$.

[18] L. Jooeun, H. Jung-Wuk, and J. Jae-Wook, “The mechanism of fracture coalescence in pre-cracked rock-type material with three flaws," Engineering Geology, vol. 233, pp. 31-47, 2017.

[19] J. Wang, G. Lin, X. Tang et al., "Failure characteristics and engineering application of layered rock with two pre-existing non-coplanar fissures," Chinese Journal of Southwest Jiaotong University, vol. 55, no. 4, pp. 719-725-732, 2020.

[20] X. P. Zhang and L. N. Y. Wong, "Cracking processes in rocklike material containing a single flaw under uniaxial compression: a numerical study based on parallel bonded-particle model approach," Rock Mechanics and Rock Engineering, vol. 45, no. 5, pp. 711-737, 2012.

[21] X.-P. Zhang and L. N. Y. Wong, "Crack initiation, propagation and coalescence in rock-like material containing two flaws: a numerical study based on bonded-particle model approach," Rock Mechanics and Rock Engineering, vol. 46, no. 5, pp. 1001-1021, 2013.

[22] C. H. Park and A. Bobet, "Crack coalescence in specimens with open and closed flaws: a comparison," International Journal of Rock Mechanics and Mining Sciences, vol. 46, no. 5, pp. 819-829, 2009.

[23] C. H. Park and A. Bobet, "Crack initiation, propagation and coalescence from frictional flaws in uniaxial compression," 
Engineering Fracture Mechanics, vol. 77, no. 14, pp. 27272748, 2010.

[24] Y. P. Li, L. Z. Chen, and Y. H. Wang, "Experimental research on pre-cracked marble under compression," International Journal of Solids and Structures, vol. 42, no. 9, pp. 2505-2516, 2005.

[25] R. H. C. Wong and K. T. Chau, "Crack coalescence in a rocklike material containing two cracks," International Journal of Rock Mechanics and Mining Sciences, vol. 35, no. 2, pp. 147-164, 1998.

[26] S.-Q. Yang, "Crack coalescence behavior of brittle sandstone samples containing two coplanar fissures in the process of deformation failure," Engineering Fracture Mechanics, vol. 78, no. 17, pp. 3059-3081, 2011.

[27] I. W. Farmer, Engineering Behaviour of Rocks, Chapman \& Hall, London, UK, 2nd edition, 1983. 